\title{
PRACTICAL REALIZATION OF ELECTRONICALLY ADJUSTABLE UNIVERSAL FILTER USING COMMERCIALLY AVAILABLE IC-BASED VDBA
}

\author{
Natchanai Roongmuanpha - Tattaya Pukkalanun - Worapong Tangsrirat ${ }^{*}$
}

Department of Instrumentation and Control Engineering, Faculty of Engineering, King Mongkut's Institute of Technology Ladkrabang (KMITL), Bangkok 10520, Thailand

\begin{tabular}{|c|c|}
\hline ARTICLE INFO & Abstract: \\
\hline $\begin{array}{l}\text { Article history: } \\
\text { Received: } 09.11 .2019 . \\
\text { Received in revised form: } 12.01 .2020 . \\
\text { Accepted: } 14.01 .2020 .\end{array}$ & $\begin{array}{l}\text { This paper describes the practical realization of electronically } \\
\text { adjustable voltage-mode universal filter with three inputs and } \\
\text { single output (TISO) using the commercially available integrated } \\
\text { circuit (IC)-based voltage differencing buffered amplifiers }\end{array}$ \\
\hline Keywords: & (VDBAs). The realization is resistor-less and contains only two \\
\hline $\begin{array}{l}\text { Voltage Differencing Buffered Amplifier } \\
\text { (VDBA) } \\
\text { Universal filter } \\
\text { Voltage-mode circuits } \\
\text { Commercially available ICs } \\
\text { Electronically adjustable }\end{array}$ & $\begin{array}{l}\text { VDBAs and two capacitors. The described filter structure can } \\
\text { realize all the five standard biquadratic filter functions from the } \\
\text { same configuration without needing any component matching } \\
\text { criterions. It also exhibits low-output impedance, which enables } \\
\text { for easy cascading in voltage-mode operation. Owing to practical } \\
\text { VDBA realization, the filter circuit can be easily made }\end{array}$ \\
\hline DOI: https://doi.org/10.30765/er.1547 & $\begin{array}{l}\text { electronically tunable with orthogonal } \omega_{o}-Q \text { tuning. The effects of } \\
\text { the VDBA non-idealities on the filter performance have been } \\
\text { analyzed in detail. To prove the theoretical finding, the } \\
\text { performance of the studied circuit was also experimentally } \\
\text { measured using the operational transconductance amplifier } \\
\text { CA3080 and the operational amplifier LF356 ICs. }\end{array}$ \\
\hline
\end{tabular}

\section{Introduction}

In the area of analog signal processing and circuit design, considerable amount of literature has been paid to the implementation of the active filters using a variety of analog active building blocks (ABBs). In 2008, among various types of analog $\mathrm{ABBs}$, the voltage differencing buffered amplifier (VDBA) and its applications for signal generations were introduced [1-6]. The VDBA belongs to a group of modern ABBs so-called voltage differencing units (VDUs), and it is a voltage counterpart of the conventional current differencing buffered amplifier (CDBA) [7]. In the VDBA, the differential input voltage, rather than current as in CDBA, is converted to the current flowing through the terminal $\mathrm{z}$ by the transconductance gain. The voltage across the terminal $\mathrm{z}$ is then transferred to the voltage at the terminal w. Since the VDBA is composed of a transconductance amplifier followed by the voltage buffered amplifier, this active element is quite suitable for applications in voltage-mode filters with electronically adjustable property. From considerable literature survey, it is found that several specific realizations of active filter using the VDBAs as ABBs have been reported [8-11]. The circuit of [8] uses only two VDBA components and two floating capacitors to implement voltage-mode universal biquad filter configuration with the three inputs and single output (TISO). Other TISO voltage-mode filter in [9] needs a floating resistor for its realization. In [10], $\mathrm{n}^{\text {th }}$-order transfer function synthesizers can realize only general $\mathrm{n}^{\text {th }}$-order allpole lowpass voltage responses. As also reported in [11], it is focused on the signal-flow-graph synthesis of general $\mathrm{n}^{\text {th }}$-order voltage transfer functions using the VDBAs. However, all the above mentioned solutions utilize the VDBA element based on different technologies like CMOS or BiCMOS, which are not commercially available and accessible in general. Therefore the behavior of the previously developed circuits has been only evaluated by computer simulation results. Also, as noted in [12], the employment of commercially available ICs is of practical advantage for such designs.

\footnotetext{
* Corresponding author

E-mail address: worapong.ta@kmitl.ac.th
} 
This communication deals with the practical TISO voltage-mode universal biquadratic filter realization using recently popularized VDBA elements. The design shows a simple realization for VDBA using commercially available chips. The realized TISO filter requires only two VDBAs and two capacitors and generates all the five standard second-order filter signals namely, lowpass (LP), bandpass (BP), highpass (HP), band stop (BS) and allpass (AP) with no need to impose component choice. The natural angular frequency $\left(\omega_{o}\right)$ and the quality factor $(Q)$ of the proposed TISO filter can be tuned electronically and orthogonally. As desired, the output voltage is obtained at the low-impedance-output terminal, which results in cascadability. The practical consideration due to the non-idealities of the VDBAs has been discussed. To examine the experimental measurements, the filter is realized with commercially available active devices operational transconductance amplifier (OTA) CA3080 and JFET input operational amplifier (Op-Amp) LF356.

\section{Description of the VDBA and its practical realization}

The symbolic notation of the VDBA is illustrated in Figure 1, where $\mathrm{p}$ and $\mathrm{n}$ are differential voltage input terminals, $\mathrm{z}$ is the current output terminal and $\mathrm{w}$ behaves as the voltage tracking terminal. Using the standard notation, the ideal terminal characteristics for the VDBA can be expressed by the following matrix expression:

$$
\left[\begin{array}{c}
i_{p} \\
i_{n} \\
i_{z} \\
v_{w}
\end{array}\right]=\left[\begin{array}{cccc}
0 & 0 & 0 & 0 \\
0 & 0 & 0 & 0 \\
g_{m} & -g_{m} & 0 & 0 \\
0 & 0 & 1 & 0
\end{array}\right] \cdot\left[\begin{array}{l}
v_{p} \\
v_{n} \\
v_{z} \\
i_{w}
\end{array}\right]
$$

where $g_{m}$ is an effective small-signal transconductance gain of the VDBA. In general, the transconductance $g_{m}$ can be tuned by externally supplied DC current providing the possibility of electronic tuning of the VDBAbased circuit's parameters. In the above expression, the differential input voltage applied across the $\mathrm{p}$ and $\mathrm{n}$ terminals $\left(v_{p}-v_{n}\right)$ is converted as a small-signal output current $i_{z}$ to the high-impedance terminal z. Here, a voltage drop at this z-terminal $\left(v_{z}\right)$ is then transferred to the output voltage $v_{w}$ via a buffered voltage amplifier with unity amplification gain.

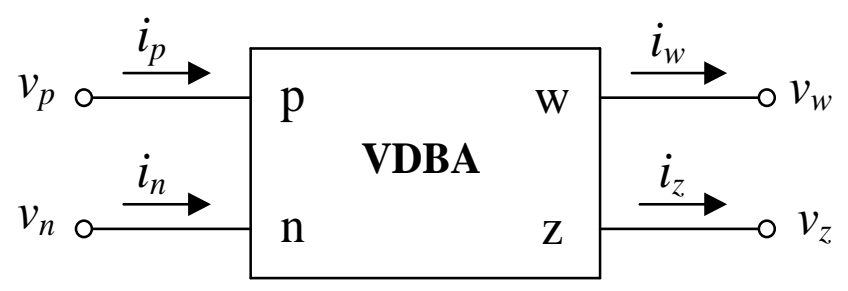

Figure 1. Electrical symbol of the VDBA.

Although the VDBA element is not commercially available as off-the-shelf ICs yet, nevertheless, it can be realized by using other commercially available IC components such as OTA and OA. Figure 2 represents the conception of the VDBA element for practical purposes constructed from commercially available IC devices. In this construction, there is OTA CA3080 by Intersil [13] and Op-Amp LF356 by Texas Instruments [14]. Thanks to the manufactured OTA, an electronic controllability of the transconductance $g_{m}$ is easily possible, in which its value is in linear dependence on the external DC biasing current $I_{B}$. In this case, the value of $g_{m}$ is determined by:

$$
g_{m}=20 I_{B}
$$




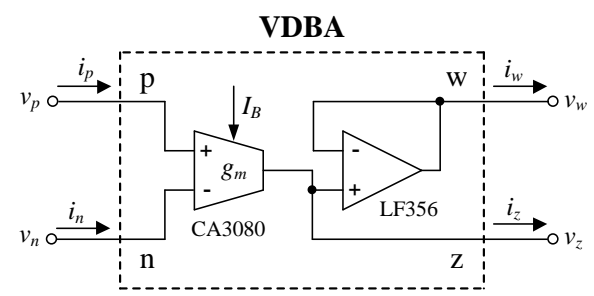

Figure 2. Practical VDBA realization with commercially available CA3080 and LF356 type ICs.

\section{Practical TISO electronically adjustable universal filter realization}

The realization of an electronically adjustable universal filter with the three input and single output terminals is shown in Figure 3, which consists of the two VDBAs and two floating capacitors $C_{1}$ and $C_{2}$. Since the circuit uses only two capacitors as passive components, it is resistorless structure. Through nodal voltage analysis, the output voltage for this TISO filter can be expressed mathematically as:

$$
V_{\text {out }}(s)=\frac{s^{2} C_{1} C_{2} V_{3}+s C_{1} g_{m 2} V_{2}+g_{m 1} g_{m 2} V_{1}}{D(s)}
$$

where

$$
D(s)=s^{2} C_{1} C_{2}+s C_{1} g_{m 2}+g_{m 1} g_{m 2}
$$

and $g_{m i}(i=1,2)$ is the transconductance gain associated with the $i$-th VDBA.

From the above relations, it can be concluded that

(1) if $V_{2}=V_{3}=0$ (grounded) and $V_{1}=$ input signal voltage, then the lowpass filter (LP) is realized with $V_{\text {out }} / V_{1}$;

(2) if $V_{1}=V_{3}=0$ and $V_{2}=$ input signal voltage, then the bandpass filter (BP) is realized with $V_{\text {out }} / V_{2}$;

(3) if $V_{1}=V_{2}=0$ and $V_{3}=$ input signal voltage, then the highpass filter (HP) is realized with $V_{\text {out }} / V_{3}$;

(4) if $V_{2}=0$ and $V_{\text {in }}=V_{1}=V_{3}=$ input signal voltage, then the bandstop filter (BS) is realized with $V_{\text {out }} / V_{\text {in }}$;

(5) if $V_{\text {in }}=V_{1}=-V_{2}=V_{3}$, then the allpass filter (AP) is realized with $V_{o u} / V_{\text {in }}$.

Therefore, all the five generic biquadratic filtering functions can be obtained at the $V_{\text {out }}$ output terminal of the proposed filter in Figure 3. Owing to the output terminal $V_{\text {out }}$ is directly taken from the terminal w of the second VDBA, the proposed filter exhibits the advantageous feature of low output impedance. Note also that there is no any matching component choice for each filter realization.

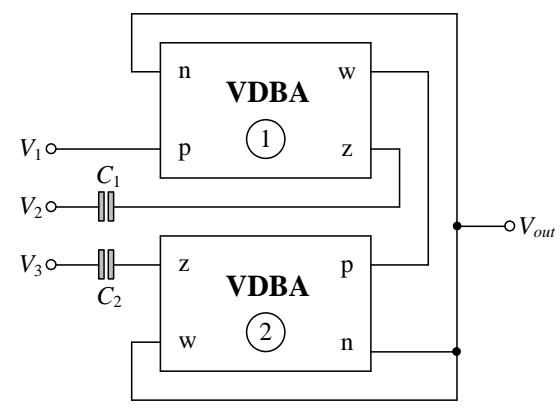

Figure 3. Proposed electronically tunable universal filter.

According to eq. (3) and (4), the natural angular frequency $\left(\omega_{o}\right)$, and the quality factor $(Q)$ of the filter are obtained as, respectively:

$$
\omega_{o}=2 \pi f_{o}=\sqrt{\frac{g_{m 1} g_{m 2}}{C_{1} C_{2}}}
$$


and

$$
Q=\sqrt{\frac{g_{m 1} C_{2}}{g_{m 2} C_{1}}}
$$

From the above expressions, they reveal that the $\omega_{0}$-value can be adjusted without disturbing the $Q$-value by setting the ratio of $\left(g_{m 1} / g_{m 2}\right)$ or $\left(C_{2} / C_{1}\right)$ invariant. Similarly, the parameter $Q$ can also be tuned independently from the parameter $\omega_{o}$ by keeping the product of $\left(g_{m 1} g_{m 2}\right)$ or $\left(C_{1} C_{2}\right)$ invariant. Therefore, the mentioned TISO configuration of Figure 3 has orthogonal controllability for the important filter parameters $\omega_{o}$ and $Q$.

\section{Non-ideality effect and circuit sensitivity analysis}

For the practical consideration, the effects of the VDBA non idealities are to be considered. In case of the non-ideal VDBA, its terminal characteristics given in eq. (1) can be rewritten as:

$$
\left[\begin{array}{c}
i_{p} \\
i_{n} \\
i_{z} \\
v_{w}
\end{array}\right]=\left[\begin{array}{cccc}
0 & 0 & 0 & 0 \\
0 & 0 & 0 & 0 \\
\alpha g_{m} & -\alpha g_{m} & 0 & 0 \\
0 & 0 & \beta & 0
\end{array}\right] \cdot\left[\begin{array}{l}
v_{p} \\
v_{n} \\
v_{z} \\
i_{w}
\end{array}\right]
$$

where $\alpha=\left(1-\varepsilon_{g m}\right)$ and $\beta=\left(1-\varepsilon_{v}\right)$. Here, $\left|\varepsilon_{g m}\right|<<1$ denotes the transconductance inaccuracy factor, and $\left|\varepsilon_{v}\right|$ $\ll 1$ represents the voltage tracking error from $\mathrm{z}$ to $\mathrm{w}$ terminal, respectively. The effects of the mentioned nonideal transfer gains of the VDBA modify the denominator $D(s)$ of eq. (4) to

$$
D(s)=s^{2} C_{1} C_{2}+s C_{1} \alpha_{2} g_{m 2}+\alpha_{1} \alpha_{2} \beta_{1} \beta_{2} g_{m 1} g_{m 2}
$$

where $\alpha_{i}$ and $\beta_{i}$ refer to the non-ideal parameters $\alpha$ and $\beta$ of the $i$-th VDBA. In this case, the $\omega_{o}$ and $Q$ of the filter are now altered to

$$
\begin{gathered}
\omega_{o}=\sqrt{\frac{\alpha_{1} \alpha_{2} \beta_{1} \beta_{2} g_{m 1} g_{m 2}}{C_{1} C_{2}}} \\
Q=\sqrt{\frac{\alpha_{1} \beta_{1} \beta_{2} g_{m 1} C_{2}}{\alpha_{2} g_{m 2} C_{1}}}
\end{gathered}
$$

The influence of variations in active and passive component values on the filter parameters $\omega_{o}$ and $Q$ can be determined by considering relative sensitivity coefficients, which are obtained to be as follows:

$$
\begin{gathered}
S_{\alpha_{1}}^{\omega_{o}}=S_{\alpha_{2}}^{\omega_{o}}=S_{\beta_{1}}^{\omega_{o}}=S_{\beta_{2}}^{\omega_{o}}=S_{g_{m 1}}^{\omega_{o}}=S_{g_{m 2}}^{\omega_{o}}=0.5 \\
S_{C_{1}}^{\omega_{o}}=S_{C_{2}}^{\omega_{o}}=-0.5 \\
S_{\alpha_{1}}^{Q}=-S_{\alpha_{2}}^{Q}=S_{\beta_{1}}^{Q}=S_{\beta_{2}}^{Q}=S_{g_{m 1}}^{Q}=-S_{g_{m 2}}^{Q}=0.5
\end{gathered}
$$

and

$$
S_{C_{1}}^{Q}=-S_{C_{2}}^{Q}=-0.5
$$

It can be easily verified from eq. (11)-(14) that all the above relative $\omega_{o}$ and $Q$ sensitivities are independent of the various circuit elements and equal to 0.5 in magnitude. Also note that, for the absolutely stable circuit, the sensitivity values of all $\omega_{o}$ and $Q$ will be no more than unity. 


\section{Experimental verification of the filter realization and discussions}

In this section, the behavior of the filter realization given in Figure 3 has been tested by experimental measurements using Agilent U8031A triple output DC power supply, and KEYSIGHT EDUX1002G digital oscilloscope. For practical implementation of the VDBA shown in Figure 2, the readily available OTA CA3080 and Op-Amp LF356 chips with $\pm 5 \mathrm{~V}$ DC supply voltages have been employed. In all measurements, the capacitor values were taken as: $C_{1}=C_{1}=1 \mathrm{nF}$.

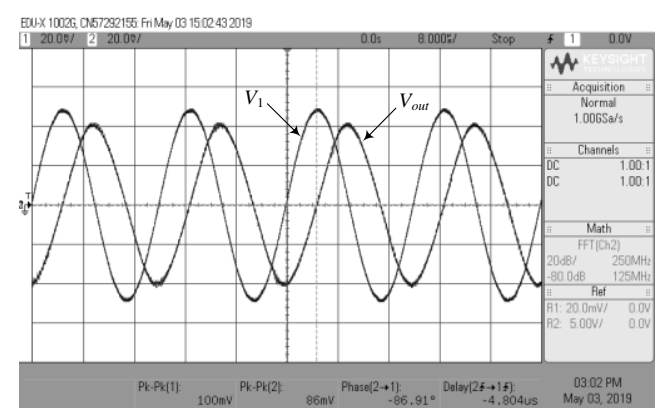

(a)

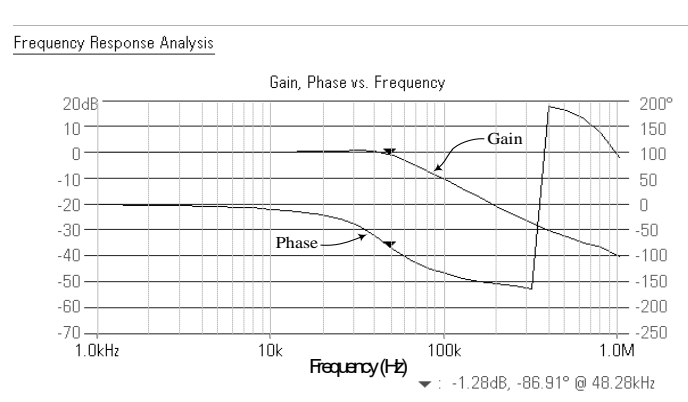

(b)

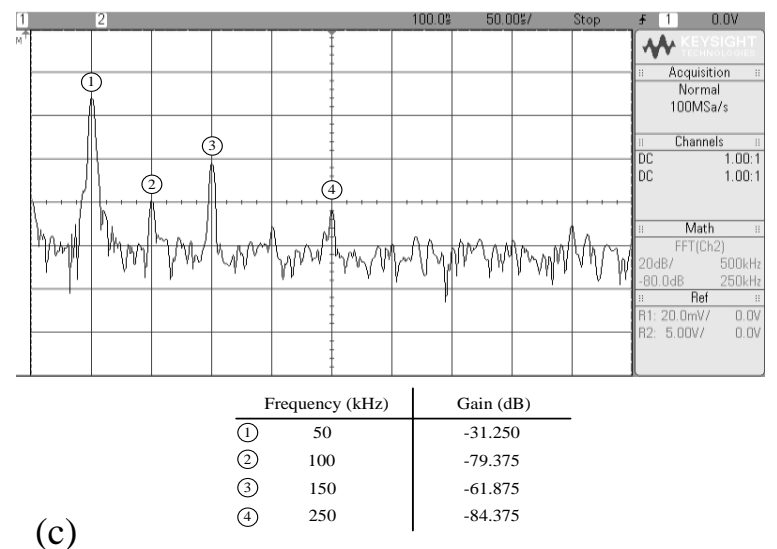

Figure 4. Experimental verification results of the LP filter in Figure 3. (a) time-domain responses (b) measured gain and phase frequency responses (c) frequency spectrum.

As an example to design the filter with the following important characteristics: $f_{o}=50 \mathrm{kHz}$ and $Q=1$, the experimental component values were set to be: $g_{m 1}=g_{m 2} \cong 0.31 \mathrm{~mA} / \mathrm{V}\left(I_{B 1}=I_{B 2}=15.5 \mu \mathrm{A}\right)$. In time-domain measurements, a $50-\mathrm{mV}$ peak sinusoidal input voltage at the operating frequency of $50 \mathrm{kHz}$ was applied to the filter. The results of the experimental verification for LP, BP, HP, BS and AP filters are respectively depicted in Figure 4-8. From these results, the errors in $f_{o}$ were measured to be less than $4.82 \%$, and the measured total harmonic distortion (THD) of each filter response is summarized in Table 1. It is, therefore, appeared that the experimental results are found to be agreed with the theoretical values, and they verify the functionality of the realized VDBA-based multifunction filter configuration. 


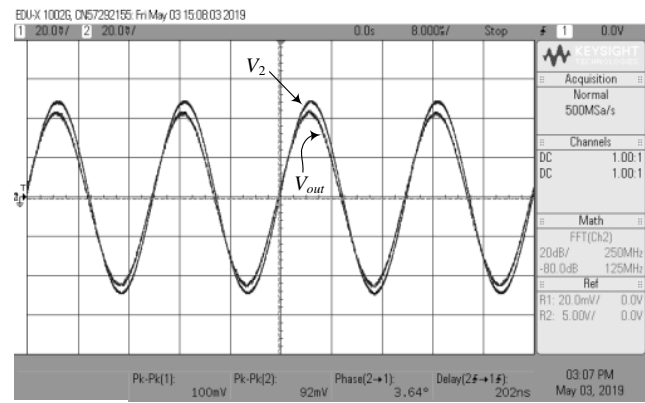

(a)

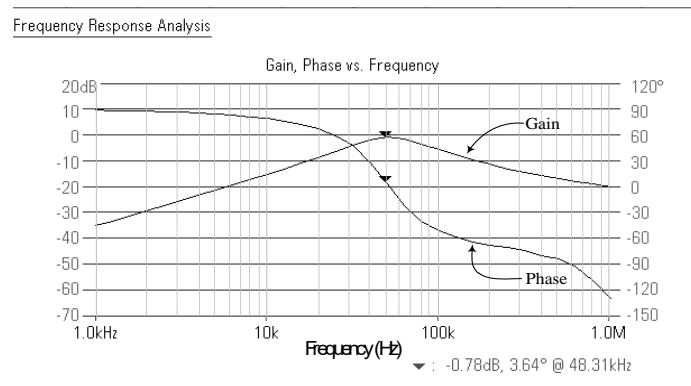

(b)

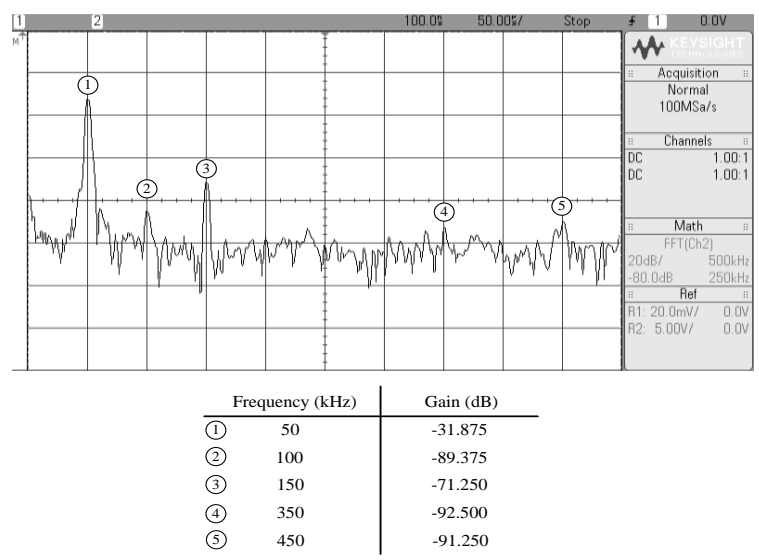

(c)

Figure 5. Experimental verification results of the BP filter in Figure 3. (a) time-domain responses (b) measured gain and phase frequency responses (c) frequency spectrum.

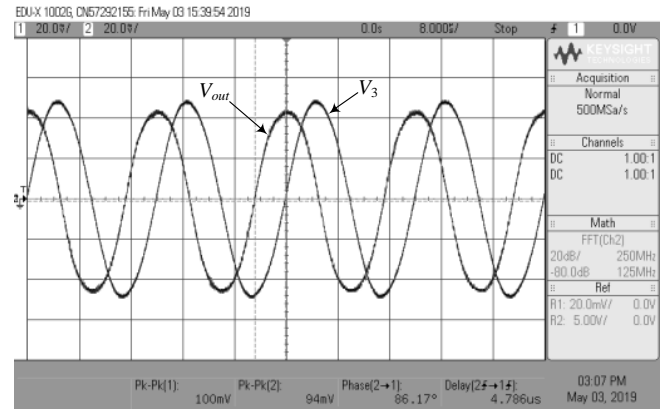

(a)

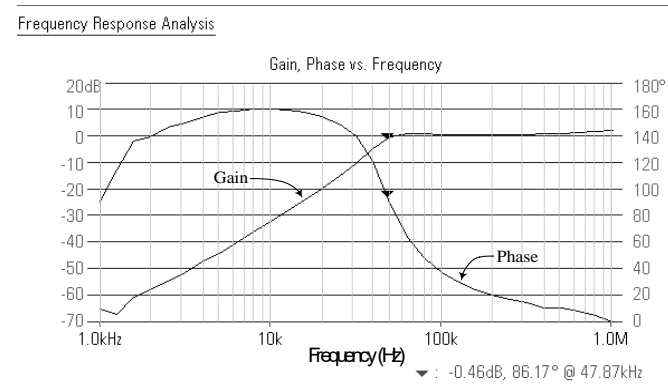

(b)

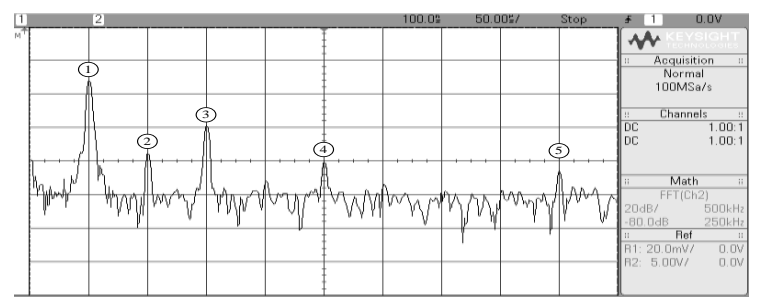

(c)

\begin{tabular}{cc|c}
\multicolumn{2}{c|}{ Frequency $(\mathrm{kHz})$} & Gain $(\mathrm{dB})$ \\
\hline (1) & 50 & -31.875 \\
(2) & 100 & -75.000 \\
(3) & 150 & -58.750 \\
(4) & 250 & -80.000 \\
(5) & 450 & -85.000
\end{tabular}

Figure 6. Experimental verifıcatıon results of the HP filter in Figure 3. (a) time-domain responses (b) measured gain and phase frequency responses (c) frequency spectrum. 
Table 1. THD of filter response.

\begin{tabular}{|c|c|}
\hline Filter type & THD $(\%)$ \\
\hline LP in Figure 4 & 2.98 \\
\hline BP in Figure 5 & 1.09 \\
\hline HP in Figure 6 & 4.61 \\
\hline BS in Figure 7 & 0.94 \\
\hline AP in Figure 8 & 0.98 \\
\hline
\end{tabular}

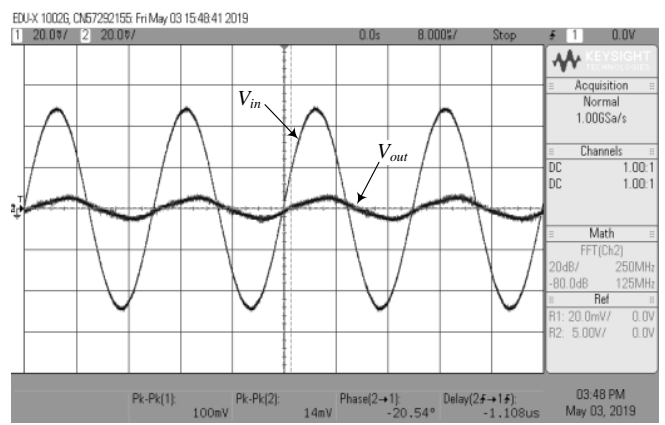

(a)

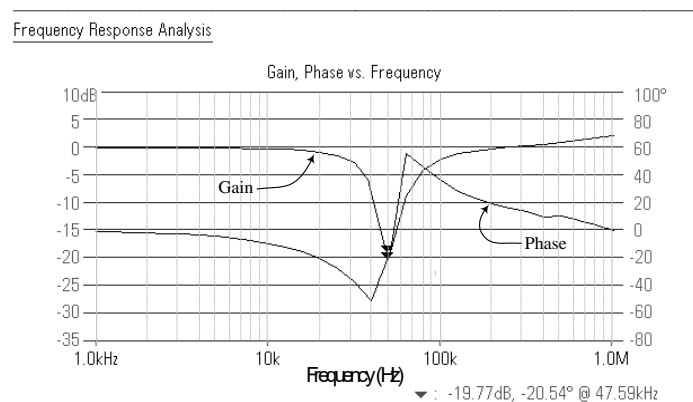

(b)

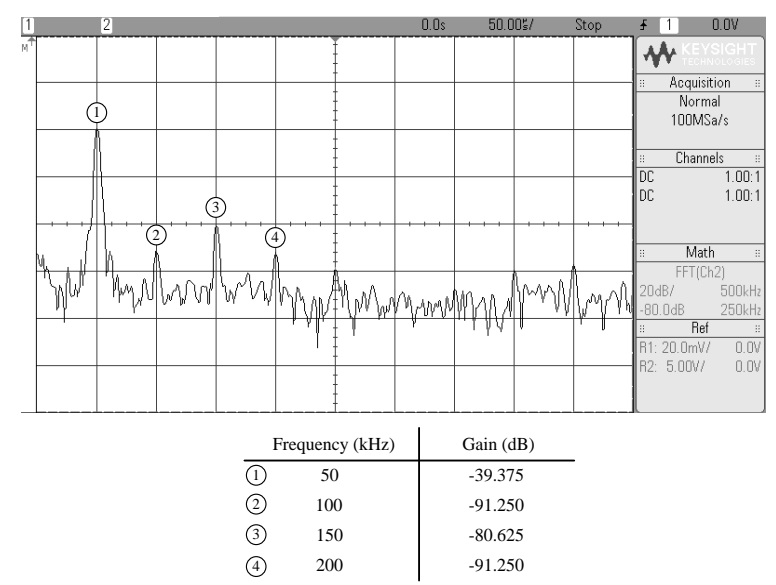

(c)

Figure 7. Experimental verification results of the BS filter in Figure 3. (a) time-domain responses (b) measured gain and phase frequency responses (c) frequency spectrum.

To demonstrate an adjustment of the $f_{o}$-value without changing the $Q$-value, the tuning BP characteristics were observed by changing the supplied currents as depicted in Figure 9. For this purpose, the DC bias currents of the VDBAs were adjusted for three different values, i.e., $I_{B}=I_{B 1}=I_{B 2}=12.5 \mu \mathrm{A}\left(g_{m} \cong 0.25 \mathrm{~mA} / \mathrm{V}\right), 25 \mu \mathrm{A}$ $\left(g_{m} \cong 0.50 \mathrm{~mA} / \mathrm{V}\right)$, and $31.5 \mu \mathrm{A}\left(g_{m} \cong 0.63 \mathrm{~mA} / \mathrm{V}\right)$, yielding $f_{o}=40 \mathrm{kHz}, 80 \mathrm{kHz}$, and $100 \mathrm{kHz}$ at $Q=1$. As can be recorded from Figure 9, the corresponding $f_{o}$ are obtained as: $38.74 \mathrm{kHz}, 78.39 \mathrm{kHz}$ and $98.25 \mathrm{kHz}$, respectively. Figure 10 also shows variation of $f_{o}$ of the proposed filter on the external control current $I_{B}$. Imperfections above these frequencies are attributed to the non-ideal gain effects and parasitic impedances of the active devices and tolerance in nominal value of the capacitor in laboratory test results. However, the proposed filter is proved to be realizable according to the experimental results despite subtle differences observed in theory. 


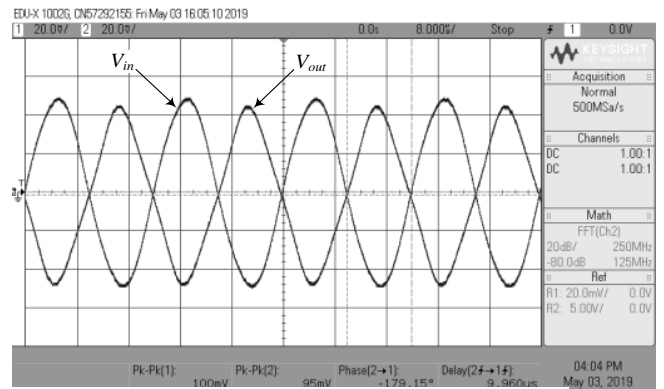

(a)

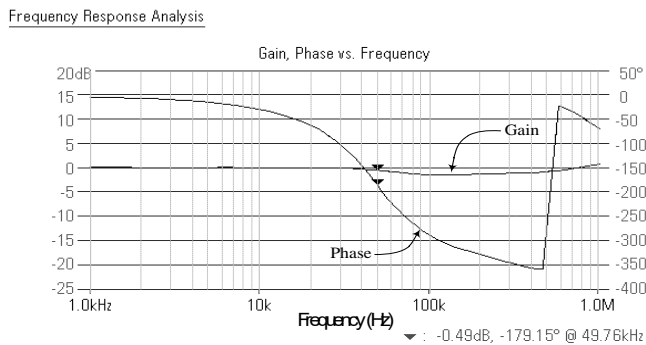

(b)

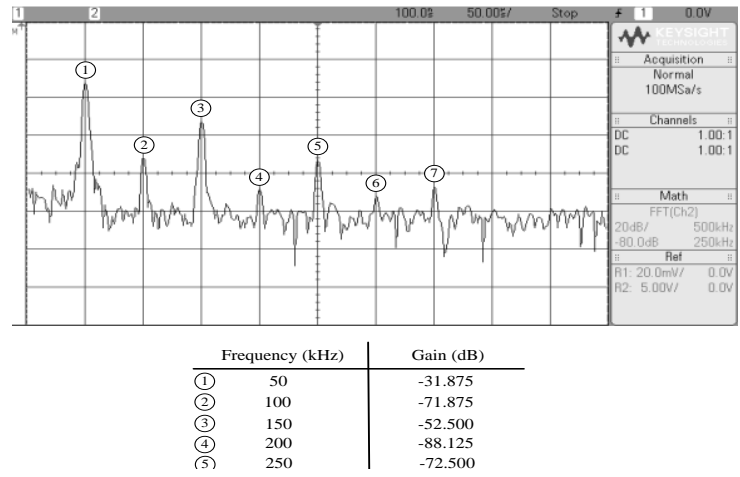

(c)

Figure 8. Experimental verification results of the AP filter in Figure 3. (a) time-domain responses (b) measured gain and phase frequency responses (c) frequency spectrum.

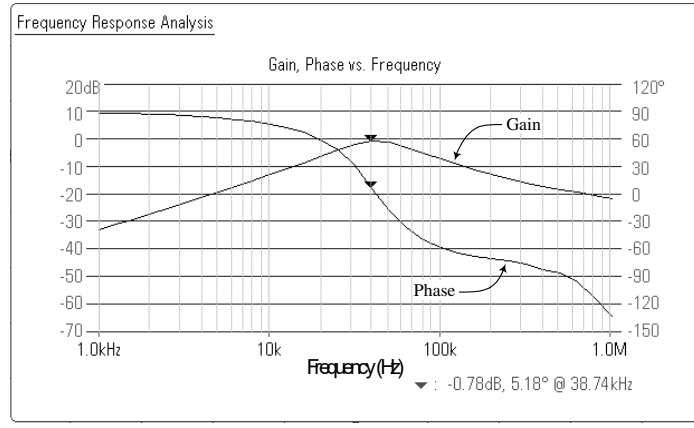

(a)

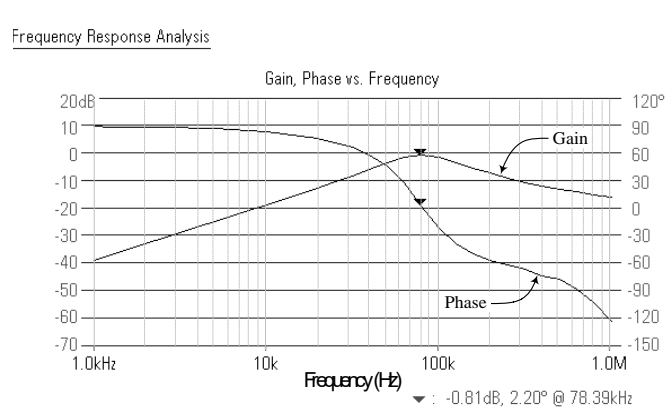

(b)

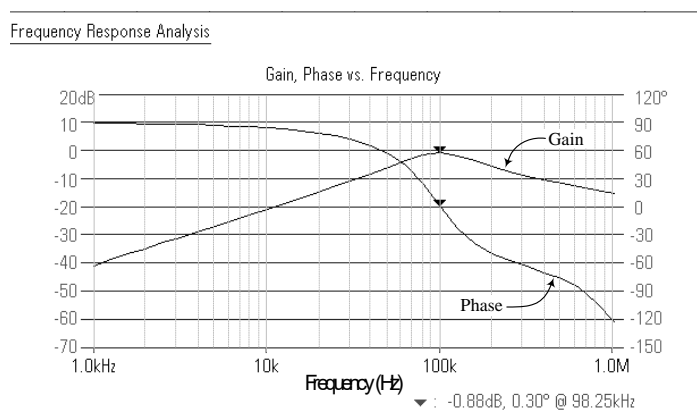

(c)

Figure 9. Measured BP frequency responses with tuning $f_{o}\left(\right.$ a) $f_{o}=40 \mathrm{kHz}$ (b) $f_{o}=80 \mathrm{kHz}$ (c) $f_{o}=100 \mathrm{kHz}$. 


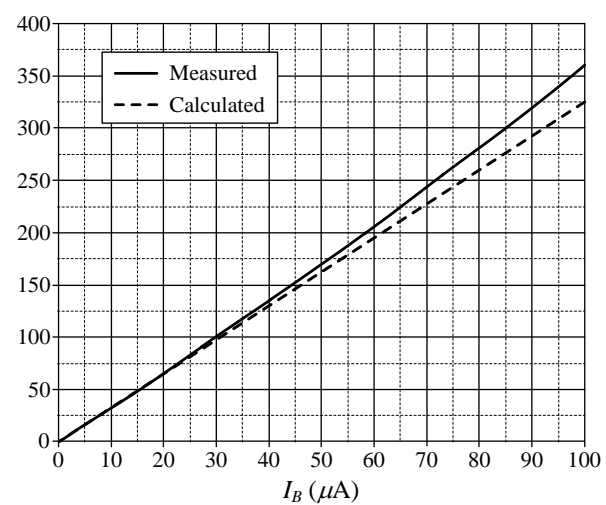

Figure 10. Dependence of $f_{0}$ on bias current $I_{B}$.

\section{Comparison with the previously published works}

A comparison of the proposed universal filter with the previously similar works published in the literature [15]-[17] is summarized in Table 2. It is observed from Table 2 that both circuits of [15-16] employ external resistors, which are not desired for fully integrated circuit (IC) technology. The circuit of [16] also suffers from the lack of electronic adjustability. Moreover, a DDCC (differential difference current conveyors) in [16] is not available commercially. The work from [17] uses a non-canonical number of active elements, i.e. 6 OTAs (operational transconductance amplifiers) and 2 MOS transistors. Accordingly, it suffers from high-power dissipation and large chip area occupation in ICs. It should be mentioned here that the proposed circuit is only the work that realizes an electronically tunable TISO universal filter using only the VDBA ABBs and capacitors, no passive resistors and does not need any component matching conditions.

Table 2. Comparison of performance of the proposed circuit with other previously published works.

\begin{tabular}{|c|c|c|c|c|}
\hline Parameter & {$[15]$} & {$[16]$} & {$[17]$} & This work \\
\hline Technology & LT1228 & $\begin{array}{c}0.5-\mu \mathrm{m} \\
\text { MIETEC }\end{array}$ & LM13600 & LT1228 \\
\hline Supply voltages & $\pm 5 \mathrm{~V}$ & $\begin{array}{c} \pm 2.5 \mathrm{~V}, \\
-1.7 \mathrm{~V}\end{array}$ & $\pm 5 \mathrm{~V}$ & $\pm 5 \mathrm{~V}$ \\
\hline No. of input & 3 & 3 & 4 & 3 \\
\hline No. of output & 1 & 1 & 1 & 1 \\
\hline Input impedance & high & high & high & high \\
\hline Output impedance & low & low & low & low \\
\hline No. active elements & LT1228 1 & DDCC $=3$ & $\begin{array}{c}\text { OTA }=6 \\
\text { MOS }=2\end{array}$ & VDBA $=2$ \\
\hline No. passive elements & $\mathrm{R}=1$ & $\begin{array}{c}\mathrm{R}=2 \\
\mathrm{C}=2\end{array}$ & $\mathrm{C}=2$ & $\mathrm{C}=2$ \\
\hline Matching requirement & no & no & no & no \\
\hline Electronic adjustability & yes & no & yes & yes \\
\hline Experimental results & yes & no & no & yes \\
\hline
\end{tabular}

\section{Conclusion}

This paper presents the practical possibility of realizing a voltage-mode biquadratic filter with three inputs and one output employing the recently introduced active element named the VDBA. The practical VDBA is realized with standard commercially available chips OTA CA3080 and OP-Amp LF 356. The presented circuit, consisting of only two practical VDBAs together with two capacitors, can realize the five standard biquadratic filter functions all at a single low-impedance-output terminal, without requiring any element-matching condition. It also exhibits the possibility of independent electronics changing of the natural angular frequency 
and the quality factor through the VDBA transconductances and has low sensitivity coefficients. The results of breadboard implementation of the proposed filter are also accomplished to validate the theoretical analysis and its practical significance.

\section{Acknowledgement}

This work was supported by the Faculty of Engineering, King Mongkut's Institute of Technology Ladkrabang (KMITL), Project number 2563-02-01-002.

\section{References}

[1] Biolek, D., Senani, R., Biolkova, V., Kolka, Z.: Active elements for analog signal processing: classification, review, and new proposals, Radioengineering, 17 (2008), 4, 15-32.

[2] Sotner, R., Jerabek, J., Herencsar, N.: Voltage differencing buffered/inverted amplifiers and their applications for signal generation, Radioengineering, 22 (2013), 2, 490-504.

[3] Tangsrirat, W., Channumsin, O.: Tunable floating capacitance multiplier using single fully balanced voltage differencing buffered amplifier, Journal of Communications Technology and Electronics, 64 (2019), 8, 797-803.

[4] Tangsrirat, W.: Actively floating lossy inductance simulators using voltage differencing buffered amplifiers, IETE Journal of Research, 65 (2019), 4, 446-459.

[5] Gupta, P., Pandey, R.: Voltage differencing buffered amplifier based voltage mode four quadrant analog multiplier and its applications, International Journal of Engineering Transaction A: Basics, 32 (2019), 4, 528-535.

[6] Tangsrirat, W.: Linearly tunable voltage differencing buffered amplifier, Revue Roumaine Des Sciences Techniques, 64 (2019), 3, 247-253.

[7] Tangsrirat, W., Katesuda Klahan, K., Teerasilapa Dumawipata, T., Surakampontorn, W.: Lowvoltage NMOS-based current differencing buffered amplifier and its application to current-mode ladder filter design, International Journal of Electronics, 93 (2006), 11, 777-791.

[8] Kacar, F., Yesil, A., Noori, A.: New CMOS realization of voltage differencing buffered amplifier and its biquad filter applications, Radioengineering, 21 (2012), 1, 333-339.

[9] Pushkar, K. L., Bhaskar, D. R., Prasad, D.: Voltage-mode new universal biquad filter configuration using a single VDIBA, Circuits, Systems and Signal Processing, 33 (2014), 1, 275-285.

[10] Tangsrirat, W., Onjan, O., Pukkalanun, T.: SFG synthesis of general $n^{\text {th }}$-order allpole voltage transfer functions using VDBAs and grounded capacitors, Proceedings of The Forth Joint International Conference on Information and Communication Technology, Electronic and Electrical Engineering (JICTEE-2014), Chiang Rai, Thailand, 2014, 291-294.

[11] Onjan, O., Unhavanich, S., Tangsrirat, W.: SFG actualization of general $n^{\text {th }}$-order voltage transfer functions using VDBAs, Proceedings of The International MultiConference of Engineers and Computer Scientists 2016 (IMECS 2016), Vol II, Hong Kong, 2016, 585-589.

[12] Maheshwari, S., Ansari, M. S.: Catalog of realizations for DXCCII using commercially available ICs and applications, Radioengineering, 21 (2012), 1, 281-289.

[13] Intersil, "2 MHz, Operational Transconductance Amplifier", CA3080 datasheet, April 2001.

[14] Texas Instruments Incorporated, “LF356-MIL JFET Input Operational Amplifier”, SNOSD55, June 2017.

[15] Klungtong, S., Thanapatay, D., Jaikla, W. : Three-input single-output voltage-mode multifunction filter with electronic controllability based on single commercially available IC, Active and Passive Electronic Components, 2017 (2017), Article ID 5240751, 10 pages.

[16] Kumngern, K., Junnapiya, S.: Voltage-mode universal filter with three-input single-output using DDCCs, Proceedings of the 2010 ECTI International Confernce on Electrical Engineering/Electronics, Computer, Telecommunications and Information Technology (ECTI CON-2010), Chiang Mai, Thailand, 2010, 746-749.

[17] Kumngern, K., Suksaibul, P., Khateb, F.: Four-input one-output voltage-mode universal filter using simple OTAs, Journal of Circuits, Systems and Computers, 28 (2019), 5, 1950078. 